\section{Physics in the developing}

\section{world}

\author{
C.N.R. Rao,
}

President of the Third World Academy of Sciences

clo The Abdus Salam International Centre for Theoretical Physics

Trieste, Italy

\begin{abstract}
The developing world includes various types of countries dif-
$I$ fering in their economic status and educational facilities. There are some that are economically poor and have very few scientists in them; there are some developing countries economically poor, but with a high percentage of educated personnel, including scientists; and there are some that are economically rich but without advanced educational and scientific institutions. The commonality amongst all these countries is the absence of a proper institutional framework and infrastructure for science although the magnitude of the deficiency varies widely. Let me briefly give a description of the kind of scenario we have today.
\end{abstract}

All the developing countries today suffer from the absence of good scientific institutions and universities. There are no developing countries today, with the exception of a few countries, such as India, China and Brazil, that have universities even somewhat comparable to those in the advanced countries. The educational institutions in most have minimal or no laboratory facilities. Scientists who are motivated to carry out good teaching and research are generally in short supply. This is particularly true of the least developed countries (LDCs). In fact, in a large number of these countries, there is almost no research or higher education opportunities in physics and other science subjects. Many of them do not have post-graduate programmes. Even in those countries which have Master's degree programmes, the conditions are poor.

The least developing countries (LDCs) require special attention. There are $49 \mathrm{LDCs}$ and most of them are in Africa. The situation in these countries is so desperate and depressing that we need to initiate a major international programme for the rejuvenation and reconstruction of institutions devoted to science and science education. I have visited some of the laboratories in the LDCs and found that even among their premier universities many of them do not have facilities comparable to those in some of the good high schools in the advanced countries. Some of the bright students there who want to take post-graduate courses and carry out research projects have no opportunities, unless they go to some other country which provides suitable encouragement. A young person from one of the LDCs was telling me recently that it is not possible to think of any experimental problem to work on within the available facilities. It is therefore necessary to initiate a programme of action which will involve not only education and re-education of teachers by providing travel fellowships and establishing exchange programmes, but also to provide optimal experimental facilities by establishing national or regional centres in these countries. The Third World Academy of Sciences has initiated a special programme which includes some of these elements. Recently, a research grant scheme has been initiated to support a few good scientists in the LDC countries, so that they are able to carry out research there: Such grants may help them to stay in these countries and not migrate to countries with scientific opportunities.
Whatever programmes we start for the developing countries in physics and other subjects will have to ensure that we concentrate on science education and capacity building as well as on steps to minimize brain-drain. Special programmes will have to be initiated to help female students and teachers to take up physics and other science subjects in these countries.

In order for new initiatives to be effective, one should promote not only North-South cooperation but also South-South cooperation. South-South cooperation has the additional advantage in that young people will be working in countries with somewhat comparable situations but with better facilities. This would help them to plan careers in the countries of their origin. A list of Centres of Excellence in developing countries is available from TWAS. These Centres should be utilized for South-South cooperation.

In conclusion, the state of science in most of the developing countries, except for some of the leading ones, is so backward that there is much that we can do.

\section{6 \\ Feedback from \\ Framework 6 proposals}

$F$ urophysics News is undertaking a survey to assess the Elevel of involvement of its readers in Framework 6 and to compile a short report on the experiences of people who submitted proposals during the first year of the programme. Sean McCarthy of Hyperion Ltd. will analyse the replies and present the results in a future edition of EPN. This information will be valuable to EPN readers in the planning of future research proposals.

1 Did you submit a proposal to Framework 6 ?

2 If you did not submit a proposal, then what were your reasons?

3 What was the most difficult part of the proposal to write?

4 Did you participate as a partner or as the coordinator of the proposal?

5 How much effort (in person days) was involved in participating in the proposal?

6 Have you any recommendation you would like to make to the European Commission regarding proposal writing for Framework 6 (and future Framework programmes)?

Please email your replies to sean.mccarthy@hyperion.ie . Participation of EPN readers will be greatly appreciated. 